\title{
Experimental Tubulogenesis Induction Model in the Mouse
}

Aleksandra Rak-Raszewska ${ }^{1 *}$

${ }^{1}$ University of Oulu, Faculty of Biochemistry and Molecular Medicine, Aapistie 5A, 90220 Oulu *correcponding author: a.rakraszewska@gmail.com or Aleksandra.Rak-Raszewska@oulu.fi

running head: MM induction 


\title{
Experimental Tubulogenesis Induction Model in the Mouse
}

\begin{abstract}
Kidney development and induction of tubulogenesis have been studied for almost seven decades.

The experimental set up of metanephric mesenchyme induction ex vivo allows to control the environment, to perform cellular manipulations and learn about renal development. Since the establishment of the ex vivo kidney culture technique in 1953, the method was modified to suit well the progress in biological and medical fields and still today present many advantages over the traditional in vivo studies.
\end{abstract}

Key words: metanephric mesenchyme induction, tubulogenesis, nephrogenesis, ureteric bud, spinal cord, $\mathrm{BIO}, \mathrm{LiCl}$ 


\section{Introduction}

The permanent (metanephric) kidneys develop from the intermediate mesoderm, which gives rise to ureteric bud (UB) and metanephric mesenchyme (MM). Reciprocal interactions of these two tissues initiate nephrogenesis which leads to development of functional units of the kidney - the nephrons ${ }^{1}$. The first experimental nephrogenesis induction was performed by Grobstein ${ }^{2,3}$ and his technique was modified later by Trowel ${ }^{4}$ and Saxen ${ }^{5}$. Grobstein showed also that neither MM nor UB survives when they are not in contact with each other ${ }^{2}$, and that MM can be induced with use of embryonic spinal cord ${ }^{6}$. Recently, this method came to a spotlight again, when Unbekandt and Davies have proposed dissociation and re-aggregation of embryonic kidneys in order to enable more efficient manipulation of cells ${ }^{7}$. It has been shown that on molecular level, the induction signal to MM is led by activation of Wnt signaling pathway ${ }^{8}$ and later that it is possible to replace it with chemical inducers such as the lithium chloride ${ }^{9,10}$, or BIO (6-Bromoindirubin-3'-oxim) ${ }^{11}$. Both chemicals inactivate the GSK3 in the "destruction complex" and allow the nuclear transfer of the $\beta$-catenin leading to activation of target genes ${ }^{11}$. The experimental tubulogenesis induction model has evolved in recent years and due to significant increase in efficiency of cellular manipulations the dissociated MM is used more often nowadays ${ }^{12}$. The induction may also be directed by application of whole UB or dissociated UB, but also can be replaced with embryonic spinal cord or chemicals. Each modification is presenting different advantages and specific uses; they are presented here.

\section{Materials}

\subsection{Dissociation of embryonic kidneys}

1. Dissected embryonic kidneys in PBS-/- on ice (see Note 1).

2. Simple light microscope, centrifuge, $15 \mathrm{ml}$ falcon tube, pipettes, pipette's tips, $40 \mu \mathrm{m}$ filters, water bath set to temp. $37^{\circ} \mathrm{C}$. 
3. Complete kidney culture medium: $10 \%$ FCS, $1 \%$ Penicilin/Streptomycin, DMEM high glucose (see Note 2). Filter the medium using $0.22 \mu \mathrm{m}$ syringe filters (see Note 3 ).

\subsection{Separation of the ureteric bud from the metanephric mesenchyme}

1. Dissected embryonic kidneys in PBS-/- on ice (see Note 1).

2. Trypsin/pancreatin solution: it is a mixture of two reagents: trypsin and pancreatin in Tyrode's solution. Measure: $0.450 \mathrm{~g}$ of trypsin (Sigma), $2 \mathrm{ml}$ of pancreatin (see Note 4), $18 \mathrm{ml}$ of Tyrode's solution (see Note 5). Dissolve trypsin on ice then measure $\mathrm{pH}$, it should be 7.4 (see Note 6).

3. Complete kidney culture medium: 10\% FCS, 1\% Penicilin/Streptomycin, DMEM high glucose (see Note 2). Filter the medium using $0.22 \mu \mathrm{m}$ syringe filters (see Note 3).

4. Dissecting microscope, needles size G27, glass dish, pipettes and pipette's tips.

\subsection{Dissociation of the metanephric mesenchyme}

1. Metanephric mesenchyme devoid of ureteric buds.

2. Dissociation solution: measure $280 \mu 1$ of $0.5 \%$ BSA in PBS (-/-) (see Note 7) and $40 \mu 1$ of Collagenase III or IV (see Note 8).

3. Complete kidney culture medium: 10\% FCS, $1 \%$ Penicilin/Streptomycin, DMEM high glucose (see Note 2). Filter the medium using $0.22 \mu \mathrm{m}$ syringe filters (see Note 3 ).

4. Dissecting microscope, low binding Eppendorf tube, pipettes and pipette's tips, incubator or water bath.

\subsection{Dissociation of ureteric buds}

1. Ureteric buds devoid of metanephric mesenchyme.

2. 1xTrypsin/EDTA solution. 
3. Complete kidney culture medium: $10 \%$ FCS, $1 \%$ Penicilin/Streptomycin, DMEM high glucose (see Note 2). Filter the medium using $0.22 \mu \mathrm{m}$ syringe filters (see Note 3 ).

4. Dissecting microscope, Eppendorf tube, pipettes and pipette's tips incubator or water bath.

\subsection{Dissection of embryonic spinal cord}

1. Cranial part of the mouse E11.5 embryo.

2. Dissecting microscope, needles size G27, PBS-/-.

\subsection{Tubulogenesis induction}

1. Dissected tissues (MM, UB) as required.

2. Complete kidney culture medium: $10 \%$ FCS, $1 \%$ Penicilin/Streptomycin, DMEM high glucose (see Note 2). Filter the medium using $0.22 \mu \mathrm{m}$ syringe filters (see Note 3 ).

3. Chemicals: $\mathrm{BIO}$ (6-Bromoindirubin-3'-oxime) or $\mathrm{LiCl}$

4. Dissecting microscope, pipettes and pipette's tips, 6-well or 12-well transwell filter dish.

\section{Methods}

\subsection{Dissociation of embryonic kidneys}

1. Place your E11.5 kidneys into $15 \mathrm{ml}$ falcon tube with $3 \mathrm{ml}$ of $1 \mathrm{x}$ Trypsin/EDTA solution (see Note 9).

2. Incubate in water bath at $37^{\circ} \mathrm{C}$ for max. $10 \mathrm{~min}$. (see Note $\mathbf{1 0}$ ).

3. Pipet vigorously every $5 \mathrm{~min}$. (see Note 11). 
4. Once you can identify single cells down the microscope and they are in majority, stop the enzymatic reaction with $7 \mathrm{ml}$ of complete kidney culture medium (see section 2.1 and Note 2). Mix well using $1 \mathrm{ml}$ pipette (see Note 11).

5. Incubate cells in the water bath at $37^{\circ} \mathrm{C}$ for further $10 \mathrm{~min}$.

6. Centrifuge the cells at $1380 \mathrm{x} g$ for $5 \mathrm{~min}$.

7. Remove supernatant and wash cells with complete kidney culture medium.

8. Filter cells using $40 \mu \mathrm{m}$ filters to remove any cell clumps (see Note 12).

9. Centrifuge the cells at $1380 \mathrm{x}$ g for $5 \mathrm{~min}$.

10. Remove supernatant and to prepare cells for further culture follow one of the protocols describe in section 3.6.

\subsection{Separation of the ureteric bud from the metanephric mesenchyme}

Once you have dissected out the embryonic kidneys you can separate the UB from the MM.

1. Treat embryonic kidneys with trypsin/pancreatin solution in PBS-/- for 30-40 sec at room temperature. It is important to thaw a tube with trypsin/pancreatin solution just before application to embryonic kidneys.

2. Stop enzymatic reaction by removing kidneys from trypsin/pancreatin solution into complete kidney culture medium (see section 2.2 and Note 2). Try to transfer as little as possible of the trypsin/pancreating solution.

3. Using dissecting microscope and needles (G27) gently remove all tissues surrounding the MM (see Figure 1 A and B), leaving only small amount to enable holding the kidney in place (docking place for needles). Use one needle to keep the kidney in place by poking into the extra tissue (to be removed later) and use other needle to remove the UB from the MM (see Note 13, Figure $1 \mathrm{C}$ ). Once the UB is out, remove that extra piece of tissue that you used to hold the kidney in place (see Figure 1D). 


\subsection{Dissociation of the metanephric mesenchyme}

Once you have clean MM, you can dissociate it to single cell suspension.

1. Transfer MM to low binding Eppendorf tube (see Note 14).

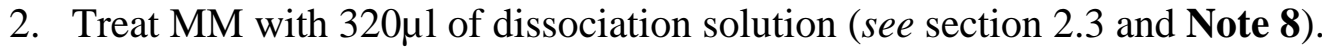

3. Place Eppendorf with $\mathrm{MM}$ into incubator $\left(37^{\circ} \mathrm{C}\right)$ for about $20-30 \mathrm{~min}$.

4. Pipette vigorously every 7-10 mins (see Note 11 ).

5. Once you can identify single cells down the microscope, stop the enzymatic reaction using $1 \mathrm{ml}$ of complete kidney culture medium (see subchapter 2.3 and Note 2).

6. Pipette well.

7. Centrifuge at $1380 \mathrm{x} g$ for $5 \mathrm{~min}$. Remember to correctly balance the centrifuge. At the end of this step, pellet of cells should be visible (see Note 15).

8. Carefully remove supernatant and wash cells again with complete kidney culture medium.

9. Centrifuge at $1380 \mathrm{x} g$ for $5 \mathrm{~min}$.

10. Remove the supernatant and to prepare cells for experiment, follow one of the protocols described in section 3.6.

\subsection{Dissociation of ureteric bud}

Once you have clean UB, you can dissociate it to single cell suspension.

1. Collect UBs into Eppendorf tube in small amount of medium, allow them to settle down, then remove excess of medium from the tube being careful not to remove the UBs (see Note 16).

2. Add $1 \mathrm{ml}$ of $1 \mathrm{x}$ Trypsin/EDTA solution, mix UBs and place them into water bath at $37^{\circ} \mathrm{C}$.

3. Incubate at $37^{\circ} \mathrm{C}$ water bath for $10 \mathrm{~min}$ (see Note $\left.\mathbf{1 0}\right)$. 
4. Pipette vigorously every $3-5 \mathrm{~min}$ (see Note 11).

5. Filter cells using 40um filters to remove any cell clumps (see Note 12).

6. The UB cells are ready to be used as inducer. Follow one of the protocols described in section 3.6 .

\subsection{Dissection of embryonic spinal cord}

The embryonic spinal cord is one of the most potent nephrogenesis inducers ${ }^{13}$.

1. Place cranial part of the embryo (head and upper body) on a glass dish filled with PBS-/and visualize under the microscope.

2. Use one needle to keep the embryo steady and the other one to separate the spinal cord from the rest of the embryo, starting right behind the brain stem (see Note 16, Figure 2A).

3. Orientate the spinal cord placing the dorsal part to the dish in order to better visualize the spinal cord and somites. Spinal cord is more dense tissue than somites and it is therefore darker than somites surrounding it (see Figure 2B).

4. Identify the border between the spinal cord and somites on right hand site and cut along using one needle (see Figure 2B (arrow) and the 2C). Repeat the same cut on the other site of the spinal cord.

5. Cut the spinal cord onto smaller pieces and use them for tubulogenesis induction as described in section 3.6

\subsection{Tubulogenesis induction}

It is well known that the MM undergoes apoptosis when the UB is not present and vice versa ${ }^{2}$. Therefore to induce the tubulogenesis in the MM it is necessary to provide the UB (whole or 
dissociated) or other tissue able to induce tubulogenesis, such as the embryonic spinal cord, or by activating the $\mathrm{Wnt} / \beta$-catenin pathway chemically. Below, detailed protocol for each option is described.

\subsubsection{With the ureteric bud}

The induction of tubulogenesis in the MM with UB may be performed by applying few alternative routes (Figure $3 \mathrm{~A}-\mathrm{C}$ ).

\subsubsection{Dissociation of whole embryonic kidneys}

1. Once you have dissociated embryonic kidney rudiments (see section 3.1), resuspend the cells in $1 \mathrm{ml}$ of complete kidney culture medium (see Note 2) and add ROCK inhibitor

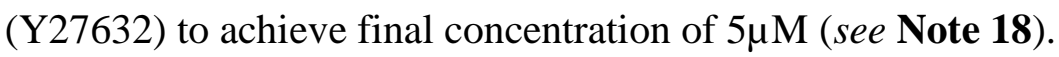

2. Count cells. Use between 100000 - 50000 cells to generate kidney pellets (see Note 19).

3. Transfer appropriate and equal amounts of medium with cells into new Eppendorf's tubes.

4. If you want to add different cell type (exogenous cells) into this kidney culture, add them now (see Note 20).

5. Centrifuge the cells at 1380x $g$ for 5 min (see Note 21).

6. Incubate pellets at $37^{\circ} \mathrm{C}$ and $5 \% \mathrm{CO}_{2}$ overnight.

7. Next day, use $1 \mathrm{ml}$ pipette to collect the pellet from the Eppendorf tube (see Note 22) and transfer it into the upper compartment of the transwell filter dish (see Note 23).

8. Transfer the plate with pellets into incubator $\left(37^{\circ} \mathrm{C}\right.$ and $\left.5 \% \mathrm{CO}_{2}\right)$.

\subsubsection{Induction of MM with whole $U B$}

Following separation of MM from UB, follow the protocol to dissociate the MM into single cell suspension (see section 3.3).

1. Transfer the UB into $3,5 \mathrm{~cm}$ culture dish. 
2. Add $1 \mathrm{ml}$ of complete kidney culture medium supplemented with GDNF (100ng/ml) and incubate at $37^{\circ} \mathrm{C}$ for $30 \mathrm{~min}$.

3. In a meantime, take dissociated MM and resuspend it in a complete kidney culture medium supplemented with BMP7 (50ng/ml) and FGF2 (100ng/ml) (see Note 25) and count the cells. Use between 100000 - 50000 cells to generate kidney pellets (see Note 19).

4. Following 30 min incubation in GDNF, transfer two UBs into each Eppendorf with 50000 cells of MM and mix well (see Note 26).

5. Centrifuge the cells at 1380x $g$ for $20 \mathrm{~min}$.

6. Place centrifuged Eppendorfs into incubator at $37^{\circ} \mathrm{C}$ and $5 \% \mathrm{CO}_{2}$ for $18-24 \mathrm{~h}$ (see Note 22).

7. The next day, transfer pellets onto transwell filters (see Notes 22, 23, 24).

8. Transfer the plate with pellets into incubator $\left(37^{\circ} \mathrm{C}\right.$ and $\left.5 \% \mathrm{CO}_{2}\right)$.

\subsubsection{Induction of MM with dissociated $U B$}

Following separation of MM from UB, follow the protocol to dissociate the MM into single cell suspension (see section 3.3) and to dissociate UB into single cells (see section 3.4).

1. Centrifuge the dissociated UB cells at 1380x g for $3 \mathrm{~min}$. to collect it at the bottom of the tube.

2. Gently remove supernatant, being careful not to remove the UB cells. Follow protocol in section 3.4.

3. Add $500 \mu \mathrm{l}$ of complete kidney culture medium supplemented with GDNF (100ng/ml) mix well to resuspend the cells and incubate at $37^{\circ} \mathrm{C}$ for $30 \mathrm{~min}$. and count the cells. Use $1 \mathrm{UB}$ cell for each 10 cells of the MM.

4. Take dissociated MM and resuspend it in a complete kidney culture medium supplemented with BMP7 (50ng/ml) and FGF2 (100ng/ml) (see Note 25) and count the cells. Use between $100000-50000$ cells to generate kidney pellets (see Note 19). 
5. Transfer appropriate amount of MM cells into Eppendorf.

6. Transfer appropriate amount of UB cells into Eppendorf with the MM cells, keeping the ratio of 1:10. Mix well.

7. Centrifuge the cells at 1380x $g$ for $20 \mathrm{~min}$.

8. Place centrifuged Eppendorfs into incubator at $37^{\circ} \mathrm{C}$ and $5 \% \mathrm{CO}_{2}$ for $18-24 \mathrm{~h}$ (see Note 22).

9. The next day, transfer pellet onto transwell filters (see Notes 22, 23, 24).

10. Transfer the plate with pellets into incubator $\left(37^{\circ} \mathrm{C}\right.$ and $\left.5 \% \mathrm{CO}_{2}\right)$.

\subsubsection{With the embryonic spinal cord}

There are other tissues than UB, known to induce tubulogenesis ${ }^{14}$ and the embryonic spinal cord is one of the most potent inducers (Figure 3D).

1. Following separation of MM from UB, follow the protocol to dissociate the MM into single cell suspension (see section 3.3).

2. Take dissociated MM and resuspend it in a complete kidney culture medium supplemented with BMP7 (50ng/ml) and FGF2 (100ng/ml) (see Note 25) and count the cells. Use between 100000 - 50000 cells to generate kidney pellets (see Note 19).

3. Transfer appropriate and equal amounts of medium with cells into new Eppendorf's tubes.

4. Centrifuge the cells at $1380 \mathrm{x} g$ for $20 \mathrm{~min}$.

5. Place centrifuged Eppendorfs into incubator at $37^{\circ} \mathrm{C}$ and $5 \% \mathrm{CO}_{2}$ for $18-24 \mathrm{~h}$ (see Note 22).

6. The next day, dissect embryonic spinal cord (E11.5) following directions in chapter 3.5.

Once you have smaller pieces of spinal cord, place them onto transwell filters (see Note 23).

7. Place Millipore $0.1-1.0 \mu \mathrm{m}$ filter on top of the spinal cord (see Note 28). 
8. Transfer pellet from Eppendorf tube onto fresh Millipore $0.1-1.0 \mu \mathrm{m}$ filter (see Note 29) and then transfer it to the transwell filter with spinal cord and Millipore filter. Position the MM directly (or as close as possible) on top of the spinal cord.

9. Transfer the plate with pellets into incubator $\left(37^{\circ} \mathrm{C}\right.$ and $\left.5 \% \mathrm{CO}_{2}\right)$.

\subsubsection{With chemicals (BIO, LiCl)}

It is also possible to replace any nephrogenesis inducing tissue with chemicals that inhibit GSK-3. This leads to cytoplasmic accumulation of $\beta$-catenin, which results in activation of target genes of the Wnt/ $\beta$-catenin pathway (Figure 3E).

1. Following separation of MM from UB, follow the protocol to dissociate the MM into single cell suspension (see section 3.3).

2. Take dissociated MM and resuspend it in a complete kidney culture medium supplemented with BMP7 (50ng/ml) and FGF2 (100ng/ml) (see Note 25) and count the cells. Use between 100000 - 50000 cells to generate kidney pellets (see Note 19).

3. Transfer appropriate number of cells into Eppendorfs.

4. Centrifuge the cells at 1380x $g$ for 20 min.

5. Following centrifugation, gently remove as much of the medium as possible and induce the pellets by adding complete kidney culture medium supplemented with either BIO $(5-10 \mu \mathrm{M})$ ${ }^{11}$ or $\mathrm{LiCl}(15 \mathrm{mM})^{9}$. Add it gently to not disrupt pellets (see Note 30).

6. Place centrifuged Eppendorfs into incubator at $37^{\circ} \mathrm{C}$ and $5 \% \mathrm{CO}_{2}$ for $18-24 \mathrm{~h}$ (see Notes 22, 31).

7. The next day, transfer pellets onto transwell filters (see Notes 23, 24).

8. Transfer the plate with pellets into incubator $\left(37^{\circ} \mathrm{C}\right.$ and $\left.5 \% \mathrm{CO}_{2}\right)$. 


\section{Notes}

1. To dissect embryonic kidneys follow the protocols described in section $\mathrm{X}$ in this MiMB book.

2. To prepare $100 \mathrm{ml}$ of complete kidney culture medium use $10 \mathrm{ml}$ of $100 \%$ Fetal Calf Serum, $1 \mathrm{ml}$ of Penicilin/Streptomycin solution (bought ready to use from e.g.: Sigma), and fill up to 100ml with DMEM high glucose $(4.5 \mathrm{mg} / \mathrm{mL})$.

3. Filtering the medium prevents it from fungal contamination and extends its use.

4. To prepare pancreatin solution measure: $0.25 \mathrm{~g}$ of pancreatin (Sigma), $0.17 \mathrm{~g}$ of NaCl and $20 \mathrm{ml}$ of $\mathrm{dH}_{2} \mathrm{O}$. Mix all components using magnetic stirrer for $3-4 \mathrm{~h}$ at RT. Then transfer to $4^{\circ} \mathrm{C} \mathrm{O} / \mathrm{N}$. Next day, centrifuge the solution for $10 \mathrm{~min}$ at 5000rpm at RT and filter the solution using $0.22 \mu \mathrm{m}$ Millipore syringe filters. Make $2 \mathrm{ml}$ aliquots and store them at $-20^{\circ} \mathrm{C}$ until needed.

5. To prepare Tyrode's solution measure: $8 \mathrm{~g}$ of $\mathrm{NaCl}, 0.2 \mathrm{~g}$ of $\mathrm{KCl}, 0.05 \mathrm{~g}$ of $\mathrm{NaH}_{2} \mathrm{PO}_{4}(\mathrm{MW}$ 137.99), $1 \mathrm{~g}$ of glucose $\left(\mathrm{H}_{2} \mathrm{O}\right.$ free, $\mathrm{D}(+)$ glucose, $\left.\mathrm{MW} 180.16\right), 1 \mathrm{~g}$ of $\mathrm{NaHCO}_{3}, 1 \mathrm{~L} \mathrm{dH}_{2} \mathrm{O}$. Dissolve all components and filter solution using $0.22 \mu \mathrm{m}$ Millipore syringe filters. Store at RT until needed.

6. The $\mathrm{pH}$ should be in range between $7.2-7.8$.

7. To prepare $100 \mathrm{ml}$ of $0.5 \%$ BSA in PBS (-/-) measure: $0.5 \mathrm{~g}$ of BSA (Sigma) and add $100 \mathrm{ml}$ of PBS calcium/magnesium free (-/-).

8. To prepare Collagenase IV solution: to original tube containing $100 \mathrm{mg}$ of collagenase 4 (Wortington Biochemical Corporation) add $4 \mathrm{ml}$ of Earle's Balanced Salt Solution, mix well and make small aliquots of ready collagenase 4 solution.

9. If older kidney rudiments are used (e.g.: E13.5 ${ }^{15}$ ), cut them with a scalpel into small pieces $(\sim 1 \mathrm{~mm} \times 1 \mathrm{~mm})$ before placing them into the Trypsin/EDTA solution. This will improve dissociation. 
10. It is important to use water bath as it is better in transferring the heat. It is also important not to prolong this incubation step as trypsin may harm the cells.

11. The pipetting should separate cell treated with trypsin/collagenase from the outer edge of the pieces, however, should not destroy cells that are already single in the solution.

12. Failing to filter the cell suspension may result in clumps of cells remaining in the suspension and generating false positive results. This may happen, because ureteric bud is epithelial structure and is difficult to dissociate into single cells suspension. Given that it is also potent inducer of the metanephric mesenchyme and the induction may take place sooner, in comparison to tissues completely devoid of ureteric bud cell clumps.

13. When separating UB from the MM with needles, try to use one needle to keep the MM in place and use the other one to remove the UB from it. If the trypsin/pancreatin solution was fresh and the kidneys were treated long enough the UB should come out of the MM intact. If you have troubles to separate the UB from the MM in one piece, you should wash the remaining pieces of kidneys with PBS-/- and treat again with fresh trypsin/pancreatin solution.

14. Using low binding Eppendorf tubes enables easy transfer of the cellular pellet, especially in cases when the pellet is very small.

15. If you place all your tubes in the centrifuge in the same direction, e.g., the tube opening towards the inside while the top holder into outer sited of the centrifuge, then you should be able to identify the site of probable cell pellet.

16. The UB is quite small tissue sample and one litter may not give you enough cells to perform induction experiments. We usually use UB from 2 or 3 litters of mice.

17. This will separate the spinal cord from the rest of the body, but it will still be connected to somites that surround it. They need to be cleaned away from the spinal cord. 
18. ROCK inhibitor is required only during first $24 \mathrm{~h}$ of culture to support epithelial cells after dissociation, but it should be removed from culture after that time elapses as in the later stages of kidney culture it is blocking the nephron development ${ }^{7}$.

19. It is possible to generate pellets from smaller number of cells (e.g., 15 000), but for unexperienced person these are very difficult to transfer from Eppendorf tube onto filter.

20. Prepare the cells in a way that they would be in single cell suspension (e.g., by trypsinization), also count the number of cells you want to use and then transfer appropriate amount into tubes with dissociated kidney cells.

21. At the end of this step you should be able to see the cell pellet that will have a shape of triangle with wide base at the bottom of the Eppendorf and a pick at the top.

22. During the overnight incubation in the Eppendorf tubes, the pellets change shape from flat to more round/spherical; this is easily detachable from the centrifuge tube.

23. Use $1 \mu \mathrm{m}$ hole size to enable easy medium flow from top to bottom compartment of the transwell filter dish. We use 12-well dishes. Fill the bottom compartment with complete kidney culture medium until small amount of medium is present also in the top compartment.

24. Collect the pellet from the medium using $1 \mathrm{ml}$ pipette trying to collect minimal amount of medium and transfer it to the upper compartment of the transwell filter dish.

25. This is also a good time if one would like to manipulate the MM cells by transduction, transfection of simply labelling the cells. In these conditions MM cells are viable and competent to respond to inductive signals for about $24 \mathrm{~h}$.

26. We use two UBs for 50000 cells, therefore if you use more MM cells to generate the pellet, use accordingly more UBs to induce it. 
27. Following that incubation time, it is recommended to change medium ${ }^{7}$; we do it by transferring the pellets into new dishes (transwell filter dishes) with fresh complete kidney culture medium.

28. This step may be omitted, but it will make it easier to separate the spinal cord from the induced MM for immunostaining and imaging purposes. At the end, the layers you will have will include: i) transwell filter membrane, ii) embryonic spinal cord, iii) Millipore filter, iv) Millipore filter, v) MM pellet.

29. When you transfer the pellet onto Millipore filter, it is good to use open forceps to hold the filter on the dish (in two places), during transfer. This is to avoid situation, in which the filter would move and get stuck to the pipette due to electrostatic forces and therefore unable the pellet transfer.

30. If you happen to disrupt the pellet when adding the induction medium, just centrifuge again at 1380x g for $20 \mathrm{~min}$.

31. We do not recommend exceeding $24 \mathrm{~h}$ mark of incubation with BIO.

\section{Acknowledgements}

I would like to thank Sanna Junttila and Paula Haipus for producing the movies from which the Figure 1 and 2 were made.

\section{References}

\section{References}

1. Saxen, L. Inductive interactions in kidney development. Symp. Soc. Exp. Biol. 25, 207-221 (1971). 
2. Grobstein, C. Inductive epitheliomesenchymal interaction in cultured organ rudiments of the mouse. Science 118, 52-55 (1953).

3. Auerbach, R. \& Grobstein, C. Inductive interaction of embryonic tissues after dissociation and reaggregation. Exp. Cell Res. 15, 384-397 (1958).

4. TROWELL, O. A. A modified technique for organ culture in vitro. Exp. Cell Res. 6, 246-248 (1954).

5. Saxen, L. et al. Differentiation of kidney mesenchyme in an experimental model system. Adv. Morphog. 7, 251-293 (1968).

6. Unsworth, B. \& Grobstein, C. Induction of kidney tubules in mouse metanephrogenic mesenchyme by various embryonic mesenchymal tissues. Dev. Biol. 21, 547-556 (1970).

7. Unbekandt, M. \& Davies, J. A. Dissociation of embryonic kidneys followed by reaggregation allows the formation of renal tissues. Kidney Int. 77, 407-416 (2010).

8. Kispert, A., Vainio, S. \& McMahon, A. P. Wnt-4 is a mesenchymal signal for epithelial transformation of metanephric mesenchyme in the developing kidney. Development 125, 4225-4234 (1998).

9. Davies, J. A. \& Garrod, D. R. Induction of early stages of kidney tubule differentiation by lithium ions. Dev. Biol. 167, 50-60 (1995).

10. Halt, K. \& Vainio, S. In vitro induction of nephrogenesis in mouse metanephric mesenchyme with lithium introduction and ureteric bud recombination. Methods Mol. Biol. 886, 23-30 (2012).

11. Kuure, S., Popsueva, A., Jakobson, M., Sainio, K. \& Sariola, H. Glycogen synthase kinase-3 inactivation and stabilization of beta-catenin induce nephron differentiation in isolated mouse and rat kidney mesenchymes. J. Am. Soc. Nephrol. 18, 1130-1139 (2007).

12. Junttila, S. et al. Functional genetic targeting of embryonic kidney progenitor cells ex vivo. $J$. Am. Soc. Nephrol. 26, 1126-1137 (2015).

13. Lombard, M. N. \& Grobstein, C. Activity in various embryonic and postembryonic sources for induction of kidney tubules. Dev. Biol. 19, 41-51 (1969).

14. Rak-Raszewska, A., Hauser, P. V. \& Vainio, S. Organ In Vitro Culture: What Have We Learned about Early Kidney Development? Stem Cells Int. 2015, 959807 (2015).

15. Rak-Raszewska, A. et al. Development of embryonic stem cells in recombinant kidneys. Organogenesis 8, 125-136 (2012).

16. Rak-Raszewska, A. \& Vainio, S. Nephrogenesis in organoids to develop novel drugs and progenitor cell based therapies. Eur. J. Pharmacol. 790, 3-11 (2016). 


\section{Figure legend}

Figure 1. Separation of the UB from the MM. A) Dissected out embryonic kidney. The dashedline surrounds the MM (everything outside the line is extra tissue to be removed). B) After removal of the extra tissue surrounding the MM, the UB is visible (dashed-line).

C) Removal of the UB from the MM. D) Separated MM and UB.

Figure 2. Dissection of the embryonic spinal cord. A) The cranial part of the embryo position to dissect out the spinal cord together with surrounding it somites. B) The spinal cord is located in between the somites. Border of these two tissues are visible and labelled with arrows. C) Cut along the border of the spinal cord and somites. D) Cleaned spinal cord.

\section{Figure 3. Schematic illustration of possible ways to induce tubulogenesis in metanephric}

mesenchyme. A) dissociation of whole embryonic kidneys - induction with dissociated UB; used to test nephrogenic potential of various exogenous cells (stem cells and others); B) induction of MM with whole UB; enable modification of MM cells; C) induction of MM with dissociated UB; enable modification of MM cells; D) induction of MM with embryonic spinal cord; enable modification of MM; E) induction of MM with chemicals; enable modification of MM (from ${ }^{16}$ modified). 